\title{
Cerebral cortical-autonomic connectivity in newborns: a first step to determine the autonomic signatures with advancing age?
}

\author{
Debra E. Weese-Mayer ${ }^{1,3} \cdot$ Renato Gonik ${ }^{2,4}$ \\ Received: 20 April 2021 / Accepted: 20 April 2021 / Published online: 19 May 2021 \\ c) Springer-Verlag GmbH Germany, part of Springer Nature 2021
}

Keywords Pediatric $\cdot$ Heart rate variability $\cdot$ Big data $\cdot$ Monitoring $\cdot$ Wireless $\cdot$ Multimodal $\cdot$ Biosensors

In this issue of Clinical Autonomic Research, Mulkey et al. report on cortical and brainstem autonomic connectivity in term newborns by measuring coherence between delta-range cortical activity and heart rate variability [8]. They base this work on previous publications by the same group using HRV metrics, high-density (HD) electroencephalography (EEG), and magnetic resonance imaging in infants with cerebral injury (caused by hypoxic-ischemic encephalopathy, perinatal stroke, and seizures) to characterize the balance of sympathetic and parasympathetic tone $[6,9]$. In their current work, they describe a topographical distribution of corticoautonomic connectivity with more robust parasympathetic than sympathetic brainstem centers, independent of the newborn state. These results invite further electrophysiological investigation into the evolution of autonomic nervous system coherence through stages of maturation, correlating with well-established patterns of EEG maturation. Additionally, a definitive assessment of coherence related to sleep-wake cycles could be determined by traditional sleep staging.

Debra E. Weese-Mayer

DWeese-Mayer@LurieChildrens.org

Renato Gonik

RGonik@UFl.edu

1 Division of Pediatric Autonomic Medicine, Department of Pediatrics, Ann \& Robert H. Lurie Children's Hospital of Chicago and Stanley Manne Children's Research Institute, 225 East Chicago Avenue, Box 165, Chicago, IL 60611-2605, USA

2 Division of Pediatric Neurology, Department of Pediatrics, UF Health Shands Children's Hospital, 1600 SW Archer Road, Gainesville, FL 32610, USA

3 Northwestern University Feinberg School of Medicine, Chicago, IL, USA

4 University of Florida College of Medicine, Gainesville, FL, USA
In this era of personalized medicine, aiming to anticipate illness when there is still adequate time for intervention in the sickest and youngest pediatric patients [1], Mulkey et al. offer an inviting and tangible portal beginning in the neonatal period. Using the same technology of HD-EEG with HRV alone or coupled with wireless wearable devices that might incorporate additional measures of the autonomic signature in the developing infant/child, the opportunities for sophisticated characterization abound. Due to their premature birth, infants born before 29 weeks' gestation "miss" the critical third-trimester autonomic nervous system maturation in utero, providing a compelling "experiment in nature" to study the autonomic maturation.

If provided, neonatal intensive care unit (NICU) monitoring with the bedside Bedmaster ${ }^{\mathrm{TM}}$ continuous data acquisition device (including monitoring of breathing, ECG, blood pressure, cerebral regional blood flow/oxygenation, hemoglobin saturation/pulse waveform, and end-tidal carbon dioxide, all on a breath-by-breath and beat-to-beat basis), both during wakefulness and sleep, can offer an opportunity for big data analysis to identify patterns of autonomic maturation. This is indeed the focus of our NIH-funded prematurity-related ventilatory control study [4]. Once discharged, whether preterm or term, wireless wearable devices with a skin-like flexible interface and wireless technology can record breathing, ECG and heart rate, temperature, pulse acceleration time (as a proxy for blood pressure), temperature, oximetry, and a proxy for cerebral regional blood flow and oxygenation during wakefulness and sleep [2, 3 , $7,10]$. With a longitudinal cohort, measures such as those described by Mulkey et al., coupled with a carefully crafted and customized wireless wearable ambulatory device, offer the potential to characterize maturation of the autonomic nervous system in terms of cardiorespiratory and cerebrovascular regulation, circadian variation of temperature, and so much more, with advancing age, all during the varied 
perturbations/activities of daily living in the home setting. By including infants who have sustained adversity, such as intermittent hypoxemia due to extreme prematurity or asphyxia-related compromise, as well as healthy older preterm infants and healthy term infants, the opportunity to study the maturation of the autonomic nervous system in sickness and health becomes an attainable proposition. Ideal to have in such a study would be an expanded, more racially and ethnically diverse cohort and inclusion of longitudinal objective measures of neurodevelopment with formal or more innovative measures such as the NIH Toolbox [5], so the results have application to all children and a connection to neurodevelopmental cognitive and behavioral outcomes.

Only then, will the vision so elegantly begun in the authors' laboratory [8] and proposed independently by others, reach its full potential with accessible and transferrable data to define the autonomic signature in the newborn period and to follow it longitudinally with advancing age. Changes in the maturational trajectory of the autonomic nervous system could then offer the opportunity for early identification and timely interventions for at-risk children with aim to improve outcomes.

Funding None.

\section{Declarations}

Conflict of interest None.

\section{References}

1. Badke CM, Marsillio LE, Carroll MS, Weese-Mayer DE, SanchezPinto LN (2021) Development of a heart rate variability risk score to predict organ dysfunction and death in critically ill children. Pediatr Crit Care Med PMID: 33710071

2. Chung HU, Kim BH, Lee JY, Lee J, Xie Z, Ibler EM, Lee K, Banks A, Jeong JY, Kim J, Ogle C, Grande D, Yu Y, Jang H, Assem P, Ryu D, Kwak JW, Namkoong M, Park JB, Lee Y, Kim DH, Ryu A, Jeong J, You K, Ji B, Liu Z, Huo Q, Feng X, Deng Y, Xu Y, Jang KI, Kim J, Zhang Y, Ghaffari R, Rand CM, Schau M, Hamvas A, Weese-Mayer DE, Huang Y, Lee SM, Lee CH,
Shanbhag NR, Paller AS, Xu S, Rogers JA (2019) Binodal, wireless epidermal electronic systems with in-sensor analytics for neonatal intensive care. Science 363:947-959

3. Chung HU, Rwei AY, Hourlier-Fargette A, Xu S, Lee K, Dunne EC, Xie Z, Liu C, Carlini A, Kim DH, Ryu D, Kulikova E, Cao J, Odland IC, Fields KB, Hopkins B, Banks A, Ogle C, Grande D, Park JB, Kim J, Irie M, Jang H, Lee J, Park Y, Kim J, Jo HH, Hahm H, Avila R, Xu Y, Namkoong M, Kwak JW, Suen E, Paulus MA, Kim RJ, Parsons BV, Human KA, Kim SS, Patel M, Reuther W, Kim HS, Lee SH, Leedle JD, Yun Y, Rigali S, Son T, Jung I, Arafa H, Soundararajan VR, Ollech A, Shukla A, Bradley A, Schau M, Rand CM, Marsillio LE, Harris ZL, Huang Y, Hamvas A, Paller AS, Weese-Mayer DE, Lee JY, Rogers JA (2020) Skin-interfaced biosensors for advanced wireless physiological monitoring in neonatal and pediatric intensive-care units. Nat Med 26:418-429

4. Dennery PA, Di Fiore JM, Ambalavanan N, Bancalari E, Carroll JL, Claure N, Hamvas A, Hibbs AM, Indic P, Kemp J, Krahn KN, Lake D, Laposky A, Martin RJ, Natarajan A, Rand C, Schau M, Weese-Mayer DE, Zimmet AM, Moorman JR (2019) Pre-Vent: the prematurity-related ventilatory control study. Pediatr Res 85:769-776

5. Gershon RC, Wagster MV, Hendrie HC, Fox NA, Cook KF, Nowinski CJ (2013) NIH toolbox for assessment of neurological and behavioral function. Neurology 80:S2-6

6. Kota S, Massaro AN, Chang T, Al-Shargabi T, Cristante C, Vezina G, du Plessis A, Govindan RB (2020) Prognostic value of continuous electroencephalogram delta power in neonates with hypoxicischemic encephalopathy. J Child Neurol 35:517-525

7. Liu C, Vogl J, Tzavelis A, Kwak SS, Chung HU, Lee JY, Kim DH, Ryu D, Li S, Irie M, Bradley A, Shukla A, Chavez C, Dunne EC, Hopkins B, Kim J, Park JB, Jo HH, Kwak JW, Madhvappathy SR, Paller AS, Xu S, Rand CM, Huang Y, Hong-Routson SJ, Marsillio LE, Weese-Mayer DE, Rogers JA (2021) Wireless, wearable devices for pediatric critical care: Proxy for continuous, noninvasive blood pressure monitoring. Adv Healthcare Mater 3:e2100383. https://doi.org/10.1002/adhm.20210038

8. Mulkey SB, Hitchings L, Persaud R, Kota S, Maxwell GL, Baker R, du Plessis A, Govindan R (2021) Cerebral cortical autonomic connectivity in low-risk term newborns. Clin Auton Res 14:1

9. Reich DA, Govindan RB, Whitehead MT, Wang J, Chang T, Kota S, du Plessis AJ (2019) The effect of unilateral stroke on autonomic function in the term newborn. Pediatr Res 85:830-834

10. Rwei AY, Lu W, Wu C, Human K, Suen E, Franklin D, Fabiani M, Gratton G, Xie Z, Deng Y, Kwak SS, Li L, Gu C, Liu A, Rand CM, Stewart TM, Huang Y, Weese-Mayer DE, Rogers JA (2020) A wireless, skin-interfaced biosensor for cerebral hemodynamic monitoring in pediatric care. Proc Natl Acad Sci USA $117: 31674-31684$ 